Article

\title{
Electronic Tongue Coupled to an Electrochemical Flow Reactor for Emerging Organic Contaminants Real Time Monitoring
}

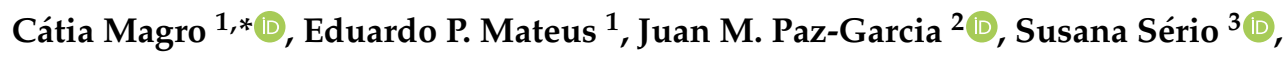 \\ Maria Raposo ${ }^{3}(\mathbb{D})$ and Alexandra B. Ribeiro ${ }^{1, *(D)}$ \\ 1 CENSE, Department of Sciences and Environmental Engineering, NOVA School of Science and Technology, \\ NOVA University Lisbon, Caparica Campus, 2829-516 Caparica, Portugal; epm@fct.unl.pt \\ 2 Department of Chemical Engineering, Faculty of Sciences, University of Malaga, Teatinos Campus, 29010 \\ Malaga, Spain; juanma.paz@uma.es \\ 3 CEFITEC, Department of Physics, NOVA School of Science and Technology, NOVA University Lisbon, \\ Caparica Campus, 2829-516 Caparica, Portugal; susana.serio@fct.unl.pt (S.S.); mfr@fct.unl.pt (M.R.) \\ * Correspondence: c.magro@campus.fct.unl.pt (C.M.); abr@fct.unl.pt (A.B.R.)
}

Received: 31 October 2019; Accepted: 2 December 2019; Published: 4 December 2019

\begin{abstract}
Triclosan, which is a bacteriostatic used in household items, has raised health concerns, because it might lead to antimicrobial resistance and endocrine disorders in organisms. The detection, identification, and monitoring of triclosan and its by-products (methyl triclosan, 2,4-Dichlorophenol and 2,4,6-Trichlorophenol) are a growing need in order to update current water treatments and enable the continuous supervision of the contamination plume. This work presents a customized electronic tongue prototype coupled to an electrochemical flow reactor, which aims to access the monitoring of triclosan and its derivative by-products in a real secondary effluent. An electronic tongue device, based on impedance measurements and polyethylenimine/poly(sodium 4-styrenesulfonate) layer-by-layer and $\mathrm{TiO}_{2}, \mathrm{ZnO}$ and $\mathrm{TiO}_{2} / \mathrm{ZnO}$ sputtering thin films, was developed and tested to track analyte degradation and allow for analyte detection and semi-quantification. A degradation pathway trend was observable by means of principal component analysis, being the sample separation, according to sampling time, explained by $77 \%$ the total variance in the first two components. A semi-quantitative electronic tongue was attained for triclosan and methyl-triclosan. For 2,4-Dichlorophenol and 2,4,6-Trichlorophenol, the best results were achieved with only a single sensor. Finally, working as multi-analyte quantification devices, the electronic tongues could provide information regarding the degradation kinetic and concentrations ranges in a dynamic removal treatment.
\end{abstract}

Keywords: triclosan; electrochemical treatment; real time monitoring; layer-by-layer technique; sputtering technique; electronic tongue; sensors

\section{Introduction}

Nowadays, both water quality and availability are under stress. The global population is expected to exceed nine-billion by 2050 , where $70 \%$ will be, living in urban areas [1]. This rising demand for water, together with poor or inefficient wastewater management and limited disposal strategies with minimal treatment practices, increases the need of sustainable tools to assure the quality, monitoring, and prosperity of a healthy population and environment [2]. Emerging organic contaminants (EOCs) are defined as "chemical substances that have no regulation and are suspected to negatively affect the environment or whose effects are unknown" [3,4]. Among EOCs, antibiotics, disinfectants, and antiseptics are especially relevant, as thousands of tons are yearly consumed worldwide in medicine, agricultural, and as daily consumer products [5]. Furthermore, the reported 
data show that conventional wastewater treatment plants are inefficient in their elimination [6-12]. Triclosan (TCS or 2,4,4'-Trichloro-2'-hydroxydiphenyl ether) is a broad antimicrobial agent, with low water-solubility (more susceptible to bio-accumulation) and that has been used for more than 50 years as an antiseptic, disinfectant, or preservative in clinical settings and several consumer products, i.e., toothpastes, cosmetics, and plastics. On the basis of the available studies, it is now accepted that it has extensive environmental and health effects, also being toxic to water living organisms due to its photodegradation to chlorodioxins $[13,14]$. TCS has been detected in wastewater treatments plants and surface waters $[15,16]$. Moreover, TCS derivatives have also been found, such as the metabolite methyl-triclosan (M-TCS) [17], which is considered to be more persistent [18] and TCS by-products, such as 2,4-Dichlorophenol (DCP) and 2,4,6-Trichlorophenol (TCP), which pose a health risk to humans and are recognized as persistent priority pollutants in the United States, Europe, and China [19].

Innovative green tools for monitoring the degradation processes are currently in the spotlight. Sensors, as compared to traditional sampling and analysis procedures, can provide fast response on the output data in a continuous, safe, and cost-effective way, and therefore may play a role in monitoring contaminants' dynamics [20]. Among sensors, the electronic tongue (e-tongue) is gaining special attention for liquid matrices. An e-tongue is a multi-sensory system, which formed by an array of sensors with low-selective thin film layers or sensorial layers, and combined with advanced mathematical procedures for signal processing based on pattern recognition and/or multi-variate data analysis [21]. E-tongues have proved to be suitable devices for monitoring aqueous environmental matrices contaminated with EOCs [22,23]. Some examples are Campos et al. (2012) [24], who developed a voltammetric e-tongue [set of noble $(\mathrm{Au}, \mathrm{Pt}, \mathrm{Rh}, \mathrm{Ir}$, and $\mathrm{Ag})$ and non-noble $(\mathrm{Ni}, \mathrm{Co}$, and $\mathrm{Cu}$ ) electrodes to the prediction of concentration levels of soluble chemical oxygen demand, soluble biological oxygen demand, ammonia, orthophosphate, sulphate, acetic acid, and alkalinity from influent and effluent wastewater. Years later, Cetó at al. (2015) [25] used a voltammetric bio e-tongue for simultaneous monitoring of catechol, $\mathrm{m}$-cresol, and guaiacol mixtures in wastewater. Thus, one of the most interesting aspects that motivate the development of e-tongues is their potential for real-time parallel monitoring of multiple species and multi-analyte determination in a single sample analysis [26,27]. The working electrodes in the e-tongues array can be covered with films (coatings), which improves the sensitivity of the electrical measurements. The ability to tune the composition of nanostructured thin films allow for an improvement in the sensor's intrinsic (chemical or physical) properties for sensing applications. The layer-by-layer (LbL) nano-assembly technique, where the Brazilian group was the pioneer in the subject [28-31], is a flexible, easily-scalable, reproducible, and versatile approach that allows for the precise control of the coating thickness, composition, and structure. This nano-assembly technique is a powerful tool for the incorporation of a wide variety of coating types, such as polyelectrolytes. The type of thin film or sensorial layer chosen is a critical step for the accomplishment of a reliable qualitative and quantitative device. In a preliminary study, Magro et al (2019) [32] found that the LbL films prepared with polyethylenimine (PEI) and poly (sodium 4-styrenesulfonate) (PSS) build up with five bilayers were suitable for TCS detection in wastewater. However, the polyelectrolyte layers of these thin films may desorb when they are immersed in solutions below $\mathrm{pH}=7$. According to Zhu et al. (2003) [33], even if the PEI degree of ionization is strongly pH dependent and the PSS is a strong polyelectrolyte, with a $\mathrm{pKa}$ near 1 , it can be influenced by solution $\mathrm{pH}$ due to the presence of a sulfonate group in its chemical structure and furthermore. Studies on layer-by-layer films that were prepared from aqueous solution with $\mathrm{pH}$ below 7 revealed that the PSS is completely ionized [34,35]. In this regard, thin films of $\mathrm{TiO}_{2}$ and $\mathrm{ZnO}$ build-up with the sputtering technique can also be considered as sensorial layers. These films proved to be efficient for the detection of molecules with phenolic rings and they presented high mechanical stability under $\mathrm{pH}$ fluctuations [36-38]. This study aimed to achieve a customized e-tongue device to follow real-time degradation and quantification of TCS and its derivative by-products in an electrochemical flow reactor (EFR) treatment. The EFR, which mimics the secondary clarifier in a wastewater treatment plant, was considered to be the most appropriate choice 
to couple with a monitoring real time tool device, due to its potential to operational implementation and final matrix conditions (non-aggressive for thin film layers, e.g., $\mathrm{pH}$ effluent around 7.6).

To attain this proof-of-concept goal: (1) an array of thin films were prepared by LbL and sputtering techniques and were characterized by a field emission scanning electron microscope, in order to understand the device response for each EOCs; (2) the impedance electrical properties of these films when immersed in effluent spiked with EOCs' were acquired; (3) "calibration curves", to individually distinguish each EOCs were the base to train the customized e-tongue; and, (4) PCA results from the e-tongue attached to a dynamic EFR were analysed to apprehend the potential for working as a monitoring real time tool for EOCs' degradation detection and semi-quantification.

\section{Materials and Methods}

\subsection{Chemical and Standards}

TCS (99\%), M-TCS (99\%), DCP (98\%), and TCP (98\%) were purchased from Sigma-Aldrich (Steinheim, Germany, Table S1). Individual stock solutions for calibration purposes were prepared with $1000 \mathrm{mg} / \mathrm{L}$ in methanol and stored at $-18{ }^{\circ} \mathrm{C}$. The methanol, acetonitrile, acetone, and formic acid used were from Sigma-Aldrich (Steinheim, Germany) in gradient grade type. Water (Type I) was from a Millipore system (Aqua Solutions, Bedford, MA, USA).

The sensor devices were purchased from DropSens (Llanera Asturias, Spain) and they were formed by either a BK7 glass solid substrate with deposited interdigitated electrodes comprising 125 "fingers" each or by a ceramic solid substrate with deposited gold interdigitated electrodes comprising eight "fingers" each. The supports' dimensions were $22.8 \times 7.6 \times 0.7 \mathrm{~mm}$ and each "finger" had 10 or $200 \mu \mathrm{m}$ of width, which was the same spacing between them. PEI and PSS from Sigma-Aldrich (St Louis, MO, USA) were the chemicals used to prepare the sensing layers on the interdigitated electrodes. The used gases argon, oxygen, and nitrogen had $\geq 99.9 \%$ of purity. The used effluent, $\mathrm{pH}(7.6 \pm 0.5)$ and conductivity $(1.6 \pm 1.0)$, was the liquid fraction that was collected in the secondary settling tank at a wastewater treatment plant (Lisbon, Portugal).

\subsection{Methods}

\subsubsection{Emerging Organic Contaminants Extraction and Quantification: Chromatography Approach}

The extraction of EOCs in the effluent was performed by solid-phase extraction (SPE) while using Oasis HLB (200 mg, $6 \mathrm{~mL}$ ) from Waters (Saint-Quentin-En-Yvelines Cedex, France). The SPE cartridges were conditioned by washing with $3 \times(6 \mathrm{~mL})$ of methanol, followed by re-equilibrium with $3 \times(6$ $\mathrm{mL}$ ) of Milli-Q water. For EOCs enrichment, the samples were acidified to $\mathrm{pH}=2$ before extraction using nitric acid. The $200 \mathrm{~mL}$ aqueous samples passed through the cartridge at a flow rate of approx. $10 \mathrm{~mL} / \mathrm{min}$ by applying a moderate vacuum, followed by a dried period of approx. $3 \mathrm{~min}$ by vacuum. The retained EOCs were eluted sequentially with $2 \times(4 \mathrm{~mL})$ of methanol and $1 \times(4 \mathrm{~mL})$ of acetone.

The EOCs determination was performed in an Agilent 1260 Infinity II high-performance liquid chromatography (HPLC) that was equipped with a quaternary pump and auto-sampler and a diode array detector (DAD)/fluorescence detector 1100 Series. An EC-C18 column (InfinityLab Poroshell 120 High Efficiency, $100 \mathrm{~mm} \times 4.6 \mathrm{~mm} ; 2.7 \mu \mathrm{m}$ with Column ID, Agilent, Santa Clara, CA, USA) was used. All of the HPLC runs were performed at a constant flow of $1.5 \mathrm{~mL} / \mathrm{min}$ in gradient mode, with the oven set to $36^{\circ} \mathrm{C}$. A mixture of acetonitrile, Milli-Q water and formic acid was used as eluents (A: $5 / 94.5 / 0.5 \%$ and B: $94.5 / 5 / 0.5 \%)$ with a gradient of $60 \%$ of B (0-2 min), followed by $97 \%$ of B (2-3.5 min) and $98 \%$ of B until $5 \mathrm{~min}$ "Calibration curves" were performed in the range between 0.5 and $20.0 \mathrm{mg} / \mathrm{L}$. The limits of detection and quantification were, respectively, 0.7 and $2.0 \mathrm{mg} / \mathrm{L}$ for TCS, 1.3 and $3.9 \mathrm{mg} / \mathrm{L}$ for M-TCS, 0.7 and $2.0 \mathrm{mg} / \mathrm{L}$ for DCP, and 1.0 and $3.0 \mathrm{mg} / \mathrm{L}$ for TCP. The recovery tests were made with fortified effluent for $1 \mathrm{~h}$ of contact time (30 min of slow agitation). The recovery percentages were between $62 \%$ and $120 \%$ in all cases. 


\subsubsection{Emerging Organic Contaminants Quantification: Customized Electronic Tongue Concept}

An array of sensor devices with different thin films that were prepared by LbL and sputtering techniques deposited onto solid substrates with gold interdigitated electrodes were coupled to an EFR (Figure 1). The e-tongue (Figure S1 for the information of the five sensors that composed the e-tongue) was used to detect the TCS, M-TCS, DCP, and TCP degradation in the effluent.

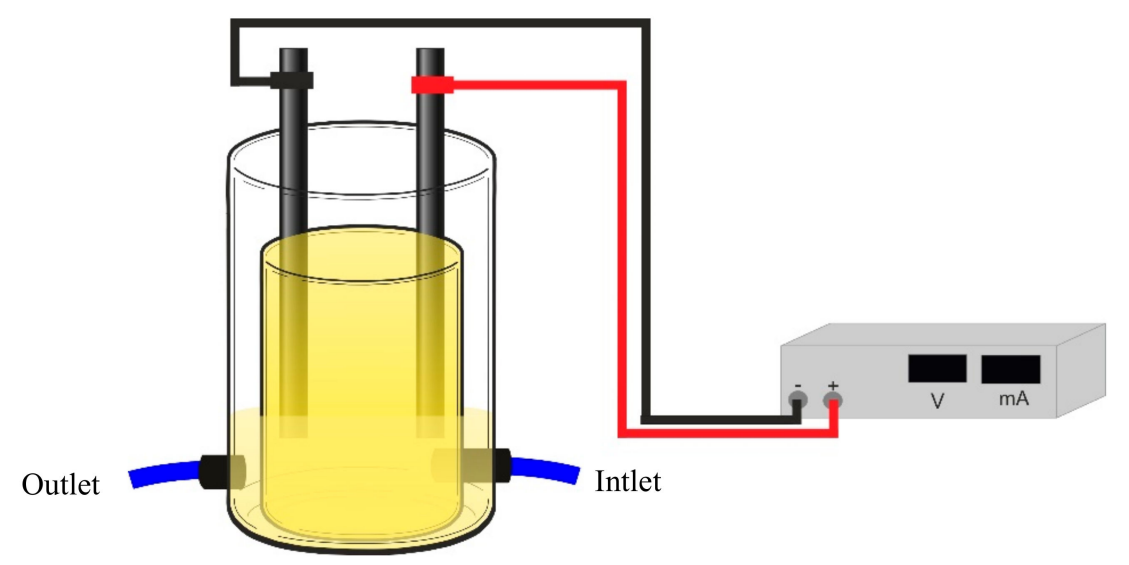

Figure 1. Electrochemical flow reactor used to attach the e-tongue.

The LbL thin films were prepared with PEI and PSS polyelectrolytes by the LbL technique [28]. Accordingly, thin films of PEI/PSS that were deposited onto solid support with gold interdigitated electrodes were obtained by adsorbing alternate layers of electrically charged polyelectrolytes at solid/liquid interface, carefully washing with water (Type I) the already adsorbed layers after immersion in the polyelectrolyte solution to remove the polyelectrolyte molecules that were not completely adsorbed. The polyelectrolytes solutions were performed with a polymeric concentration of $10^{-2} \mathrm{M}$ diluted in water Type I, produced with a Millipore system (Bedford, MA, USA). The adsorption time period of each layer (immersion time in each polyelectrolyte solution) was $30 \mathrm{~s}$ and the thin film was dried [39] while using a nitrogen flow after the adsorption of each layer. The aforementioned sequence was repeated five times in order to obtain a film with five bilayers, denoted as (PEI/PSS) 5 .

Monolayered films: $\mathrm{TiO}_{2}, \mathrm{ZnO}$ and bilayered film: $\mathrm{TiO}_{2} / \mathrm{ZnO}$ (being $\mathrm{ZnO}$ the upper layer) were deposited at room temperature onto gold interdigitated electrodes glass substrates $(22.8 \times 7.6 \times$ $0.7 \mathrm{~mm}$ ), by DC (voltage source, Huttinger PFG 10000) reactive magnetron sputtering in a custom-made system. Tianium and zinc discs (Goodfellow, 99.99\% purity) with $64.5 \mathrm{~mm}$ of diameter and $4 \mathrm{~mm}$ of thickness each were used as the sputtering targets. A turbomolecular pump (Pfeiffer TMH 1001) was used to achieve a base pressure of $10^{-4}-10^{-5} \mathrm{~Pa}$ (before introducing the sputtering gas). Before the sputter-deposition step of the films, a movable shutter was interposed between the target and the substrates. The target was pre-sputtered in the Ar atmosphere for $2 \mathrm{~min}$ to clean the target surface. The target-to-substrate distance was kept constant at $100 \mathrm{~mm}$. Gases in the system were pure $\mathrm{Ar}$ and $\mathrm{O}_{2}$ and needle valves separately controlled their pressures. $\mathrm{TiO}_{2}$ and $\mathrm{ZnO}$ depositions were both carried out in $100 \% \mathrm{O}_{2}$ atmosphere. For the $\mathrm{TiO}_{2}$ film the total pressure was kept constant at $2 \mathrm{~Pa}$, the sputtering power was $530 \mathrm{~W}$, and the deposition time was $25 \mathrm{~min}$. In the case of $\mathrm{ZnO}$ film, the total pressure was fixed at $4.8 \mathrm{~Pa}$, the sputtering power was $300 \mathrm{~W}$, and the deposition time was $30 \mathrm{~min} . \mathrm{TiO}_{2} / \mathrm{ZnO}$ bilayered films were prepared while using the aforementioned deposition conditions for $\mathrm{TiO}_{2}$ and $\mathrm{ZnO}$. No external substrate heating was used during the deposition. The substrate temperature was measured by a thermocouple passing through a small hole in a copper piece that was in contact with the substrate. During the deposition process, the sample temperature increased up to $60^{\circ} \mathrm{C}$ due to the plasma particle bombardment of the substrate. The characterization of the thin films thickness and morphology was performed by a field emission scanning electron microscope (FEG-SEM JEOL 7001F) operating at $15 \mathrm{keV}$. A gold thin film was coated on the films surface before SEM analysis to charge 
build-up prevention. The images of the cross section allowed for the estimation of the films' thickness. Therefore, the measured thickness is given by the trigonometric equation since the positioning of the sample has a slope relative to the axis of incidence of the electron beam which can be deduced through the geometry involved. The indicated correction was calculated while using Equation (1).

$$
d_{S E M}=\frac{d_{o b s}}{\cos \alpha}
$$

where the $d_{S E M}$ is the real thickness, $d_{o b s}$ is an average of the measured thickness values estimated from the cross-section images and $\alpha$ is the beam incident angle $\left(20^{\circ}\right)$.

The electrical analysis of the aqueous matrices was performed by measuring sequentially the impedance spectra of each sensor device when immersed (about 3 min each) in effluent with different EOCs concentrations, while using a Solartron 1260 Impedance Analyzer (Solartron Analytical, AMETEK scientific instruments, Berwyn, PA, USA) in the frequency range of $1 \mathrm{~Hz}$ to $1 \mathrm{MHz}$, while applying an AC voltage of $25 \mathrm{mV}$. The impedance data was collected from the SMaRT Impedance Measurement Software (AMETEK scientific instruments, Berwyn, PA, USA). Calibration solutions were performed at $25{ }^{\circ} \mathrm{C}$ and then prepared while using effluent spiked with EOCs concentrations in the degradation range that were expected in the electrochemical flow reactor $(0$ to $0.8 \mathrm{mg} / \mathrm{L})$. For all measurements a blank standard $(0 \mathrm{mg} / \mathrm{L})$ was used. For the electro-degradation monitoring, every $15 \mathrm{~min}$ (total time of treatment $120 \mathrm{~min}$ ) was assembled an aliquot to be measured for each sensor, in the impedance conditions that are described above.

\subsubsection{Data Analysis}

Principal component analysis (PCA) was carried out regarding the normalized Z-score normalization, $z=\frac{x-\mu}{\sigma}$ impedance spectroscopy data (capacitance, impedance, imaginary, and real and loss tangent measurements), where $x$ is the mean of three impedance measurements at a fixed frequency, $\mu$ the average of all the frequency ranges, and $\sigma$ the standard deviation of all the frequency ranges. PCA was the choice of data proceeding to reduce the size of data and obtain a new space of orthogonal components, in which different concentration patterns can be observed and explained with Excel XLSTAT Programme. All of the sample analyses were carried out in duplicate or triplicate.

\section{Results and Discussion}

\subsection{Sensors Characterization: Morphology and Thickness}

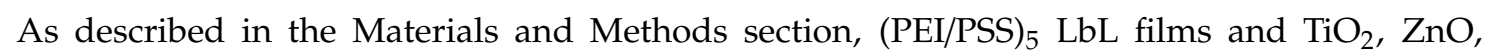
and $\mathrm{TiO}_{2} / \mathrm{ZnO}$ sputtered films (see sensors composition in Figure $\mathrm{S} 1$ in Supplementary Materials) were prepared and characterized. Figure $2 \mathrm{a}, \mathrm{b}$ presents the SEM images and the respective thickness of those thin films. The characterization of the sensors layers is important to explain the sensors performance, since the homogeneity, particle size, and thickness will affect the electrical measurements: resistance, molecules' adsorption, capacitance, and further capability of detection.

In agreement with Figure 2a, glass conducting substrates are covered by homogeneous films. However, the surface morphology of these films changes according to the deposition technique. Thus, the LbL films exhibited a smooth surface with evidence of very small agglomerates or grains. On the contrary, sputtering films presented a rougher surface and much larger agglomerates with different shapes, depending on the oxide used. In particular, for $\mathrm{TiO}_{2}$ films, the agglomerates of grains with an average lateral size of $30 \mathrm{~nm}$ are distributed over the substrate surface with a 'blooming flower-like' appearance. In the case of $\mathrm{ZnO}$ films, the surface presents a pronounced cone-like morphology and lateral average size of approximately $100-120 \mathrm{~nm}$. The outermost $\mathrm{ZnO}$ layer of the $\mathrm{TiO}_{2} / \mathrm{ZnO}$ bilayered films show globular shape agglomerates, with the lateral average size approximately 100-150 nm. The formation of agglomerates or particulates are a product of individual nano-phase grains that exhibit different dimensions $\left(\mathrm{ZnO}>\mathrm{TiO}_{2}\right)$, which result in an increase of the active surface area and 
also promotes the formation of porous films. These characteristics are critical in the response device to EOCs detection. The films thickness was evaluated from FEG-SEM cross-section images and Figure $2 b$ summarizes the obtained values. It can be observed that the thickness of the (PEI/PSS) $, \mathrm{TiO}_{2}, \mathrm{ZnO}_{\text {, }}$ and $\mathrm{TiO}_{2} / \mathrm{ZnO}$ increases from 133 to $713 \mathrm{~nm}$, in the mentioned order.
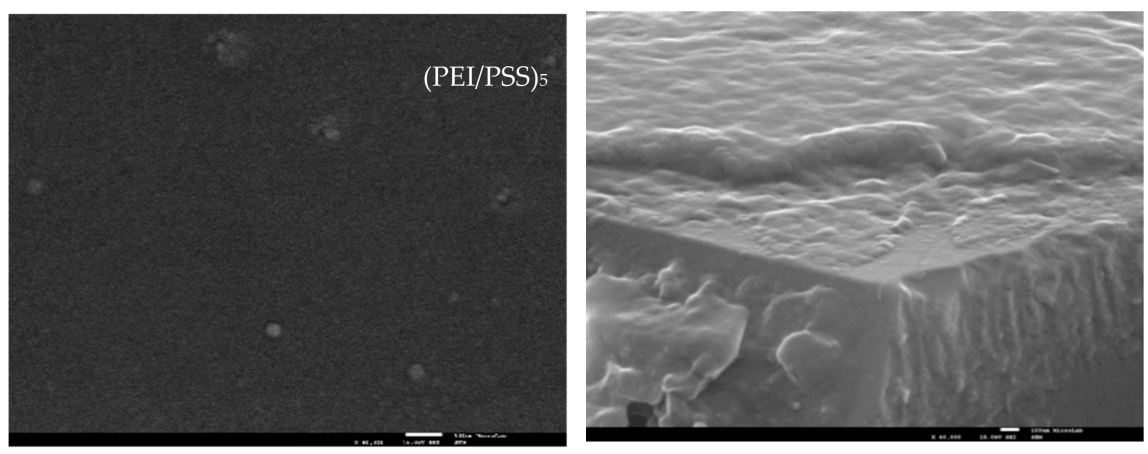

Thickness

(nm)
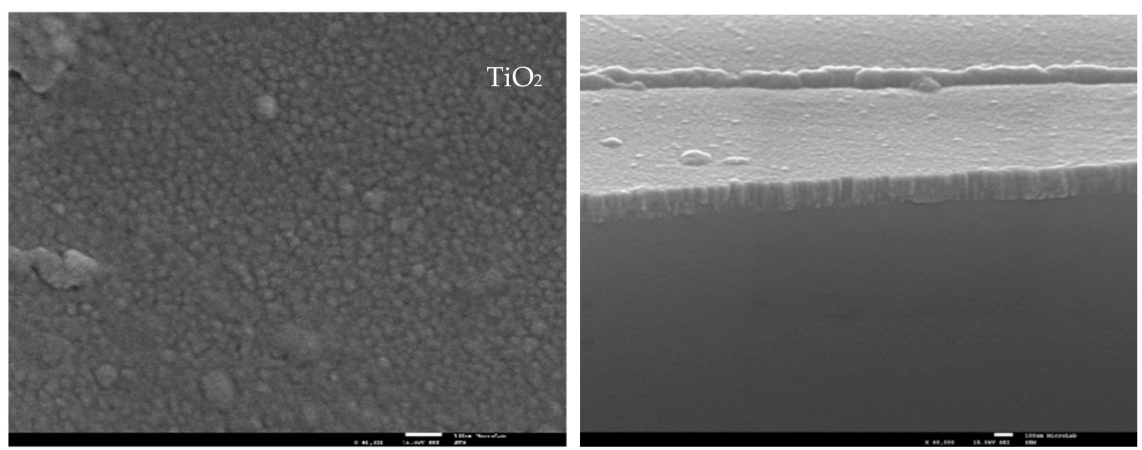

$138 \pm 6$
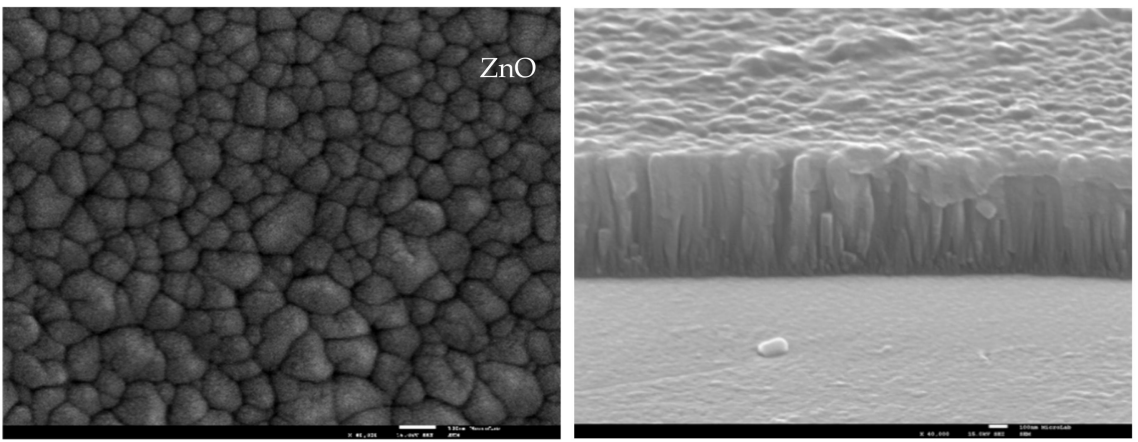

$160 \pm 4$

$665 \pm 8$

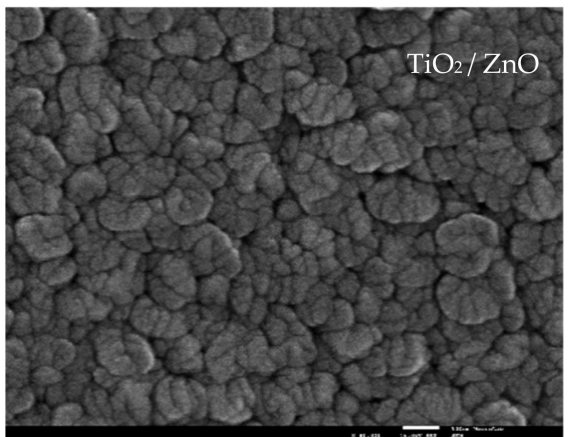

(a) Top section

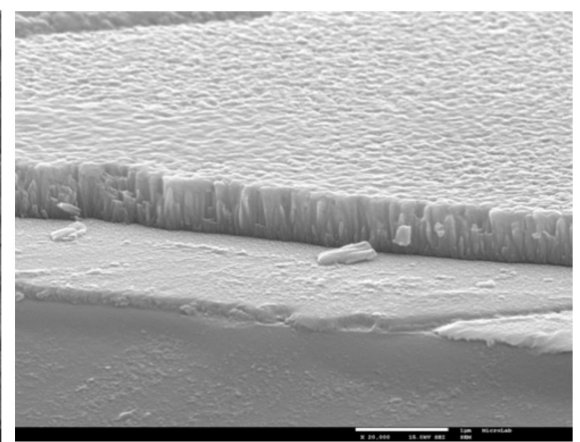

(b) Cross Section

Figure 2. Scanning electron microscope (SEM) image of (PEI/PSS) $\mathrm{TiO}_{2}, \mathrm{ZnO}$ and $\mathrm{TiO}_{2} / \mathrm{ZnO}$ thin films combinations: (a) Top and (b) cross section. 


\subsection{E-Tongue Training for Emerging Organic Contaminants Recognition}

To train the e-tongue device, it is first necessary to find the "calibration curves" for the individual compounds. For that, i.e. to analyze their degradation pathway, impedance spectra of the sensors when immersed in effluent spiked with the EOCs, at different concentrations, were acquired.

The PCA method was applied to carry out an exploratory analysis of the obtained impedance data, though the reduction of the size of data and the creation of a new space of orthogonal components, in which different concentration patterns can be observed. Figure 3 presents the PCA score plot of the measured impedance data (see spectra in Figure S2 in the Supplementary Materials), obtained when the five sensors (composition on Figure S1 in Supplementary Materials; (PEI/PSS) $)_{5}$ onto $10 \mu \mathrm{m}$ interdigitated electrode, (PEI/PSS) 5 onto $200 \mu \mathrm{m}$ interdigitated electrode, $\mathrm{TiO}_{2}$ onto $10 \mu \mathrm{m}$ interdigitated electrode, $\mathrm{ZnO}$ onto $10 \mu \mathrm{m}$ interdigitated electrode, and $\mathrm{TiO}_{2} / \mathrm{ZnO}$ onto $10 \mu \mathrm{m}$ interdigitated electrode) were immersed in effluent that was spiked with the four EOCs at different concentrations. Correspondingly, the reproducibility of the measurements for the lowest concentrations $(0.1 \mathrm{mg} / \mathrm{L}$, more susceptible to error), for each sensor for each compound can be observed in Figure S3 (in Supplementary Materials).

\section{Increased on EOCs concentration}

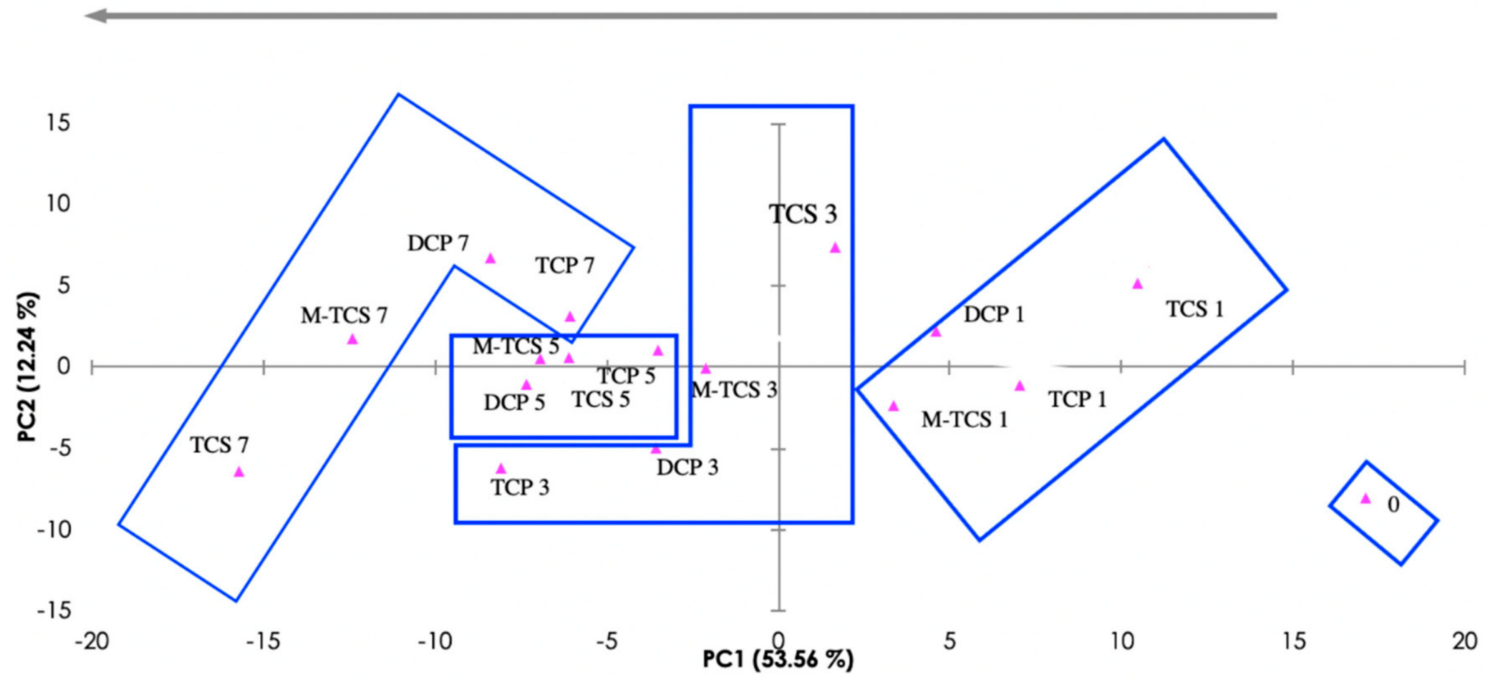

Figure 3. Principal component analysis (PCA) Score plot for the electronic tongue (five types of sensors) for 2,4,6-Trichlorophenol (TCP), 2,4-Dichlorophenol (DCP), triclosan (TCS), and metabolite methyl-triclosan (M-TCS)) individual measurements in the range of concentration $0,1,3,5,7$, that correspond to the effluent as sampled, and effluent spiked with 0.1, 0.3, 0.5 and $0.7 \mathrm{mg}$ emerging organic contaminants/L (EOCs/L).

On the PCA plot, as shown in Figure 3, the resulting analyte clustering by concentration are represented. The first two components of the PCA explain $65.80 \%$ of the observed variation. The plot observation supports the ability of the e-tongue device to "recognize" between individual EOCs-spiked effluents and raw effluent (non-spiked) matrices. A trend along the first component (PC1), according to the analyte concentrations might be observed on the plot, where the concentration increases from right to left across $\mathrm{PC} 1$ axis, moving away from concentration zero, and thus supporting the potential of the e-tongue device to discriminate quantitatively individual EOCs.

It was possible to determine individual "calibration curves" through the first two principal components data (Figure S4 in Supplementary Materials). These estimated curves are useful tools for a semi-quantitative extrapolation of the EOCs' during EFR monitoring, where the effluent has a mix contamination. It was observed that the best fitting is not linear, as it is usually demanded and seen in chromatography methods [28], but polynomial, where the measure of goodness-of-fit observed ranged from $R^{2}=0.86(T C P)$ to $R^{2}=0.99$ (TCS). 


\subsection{E-tongue Performance for Emerging Organic Contaminants Semi-Quantification}

Figure 4 shows the PCA plot from the normalized impedance data that were obtained by the customized e-tongue for the EFR treatment dataset. The dataset is composed by the analysed aliquots that were collected every $15 \mathrm{~min}$ in the course of the EFR treatment $\left(120 \mathrm{~min} ; \mathrm{t}_{0}-\mathrm{t}_{120}\right)$. A pattern in the plot, through the two first principal components, related to the time of EFR treatment is identifiable. The first two components of the PCA explain $77.27 \%$ of the observed variation. This observable trend supports the device responsiveness towards the EOCs decreasing concentration (observation that is supported by HPLC data) across time. The trend follows a similar behaviour from that observed for the individual EOCs measurements, as on the mixed EOCs measurements are the highest concentrations that drift away from concentration zero (see Figure S5 in Supplementary Materials). As noted for the individual EOCs calibration plot (Figure 3), the e-tongue, when monitoring the mixed EOCS in the effluent (Figure 4), is also able to "recognize" between EOCs-spiked effluent and raw effluent (non-spiked) matrices.

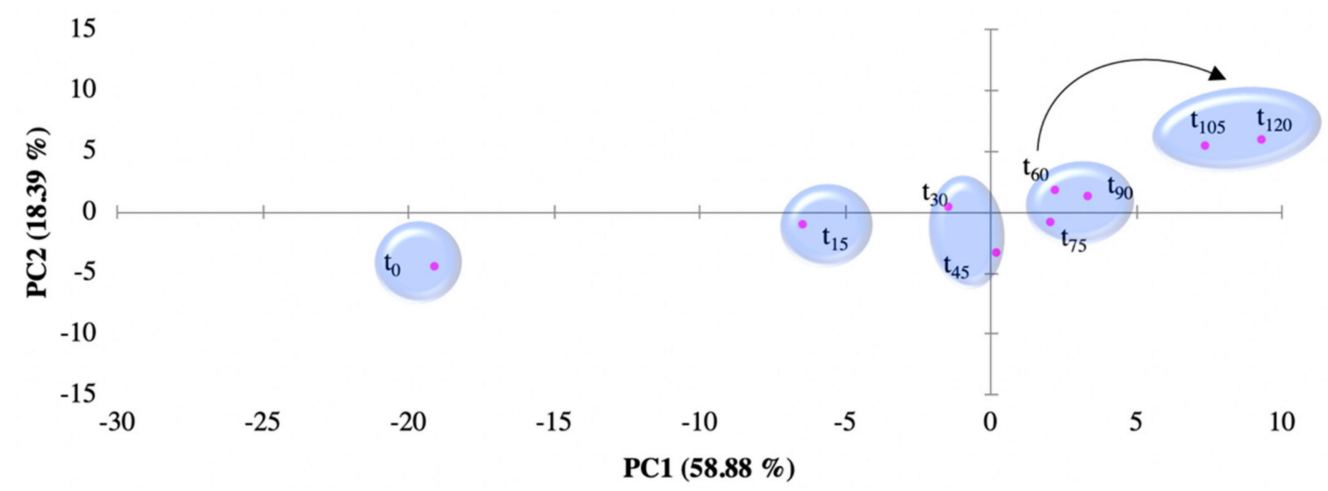

Figure 4. PCA Score plot for electrochemical flow reactor (EFR) degradation path measured by the electronic tongue in the effluent spiked with the four EOCs: $t_{0}$ to $t_{120}$ correspond to sampling every $15 \mathrm{~min}$.

A three-dimensional (3D) plot was developed (Figure 5), by adding to the PC1 and PC2 data axis, a $\mathrm{Z}$ axis with the EOCs concentration values $\mathrm{t}_{0}$ cross-check the individual EOCS e-tongue semi-quantitative "sensorial signal" (Figure 3) with the mixed EOCs "sensorial signal" at the end of EFR treatment (Figure 4). The purpose of adding the $\mathrm{z}$ axis was to allow for a visual evaluation of the concentration range dimension obtained for the EOCs at the end of EFR treatment. Three parameters compose the plot data: (1) the EOCs estimated concentrations by HPLC at $\mathrm{t}_{120}(\mathrm{TCP}=0.3 \mathrm{mg} / \mathrm{L}$; $\mathrm{DCP}=0.45 \mathrm{mg} / \mathrm{L} ; \mathrm{TCS}=0.03 \mathrm{mg} / \mathrm{L} ;$ and, M-TCS $=0.29 \mathrm{mg} / \mathrm{L}$ ) and $(2)$ the PC1 and PC2 data attained from Figure 4 at $\mathrm{t}_{120}$ (pink dots); (3) the interpolated PC1 and PC2 values from the data in Figure 3 that are close to the HPLC estimated concentrations $(\mathrm{TCP}=0.3 \mathrm{mg} / \mathrm{L} ; \mathrm{DCP}=0.5 \mathrm{mg} / \mathrm{L} ; \mathrm{TCS}=0.0 \mathrm{mg} / \mathrm{L}$; and, M-TCS $=0.3 \mathrm{mg} / \mathrm{L}$ ) for each of the EOCs at $\mathrm{t}_{120}$ (blue dots)

It is observed on Figure 5 that, for TCS and M-TCS, the distance between the interpolation points and the calibration points was lower, when compared with DCP and TCP. It is important to refer that TCP and DCP are the most common by-products for the TCS and M-TCS degradation pathway, and thus they are created at the same time that they are degraded, which might explain the experimental results for these compounds.

Additionally, it was also important to understand which individual sensor, of the multi sensor e-tongue, had the higher influence in the impedance "sensorial signal" for each EOCs. Thus, for TCS and M-TCS, the best response was obtained with $\mathrm{TiO}_{2} / \mathrm{ZnO}$, with the first two components of the PCA explaining $96.65 \%$ and $96.92 \%$ (see PCA data on Supplementary Materials, Figure S6a,b) of the total variance, respectively. For TCP, the best semi-qualitative analysis was achieved while using the $\mathrm{TiO}_{2}$ sensor, with the first two components of the PCA explaining $99.96 \%$ (see PCA data on Supplementary Materials, Figure S6c) of the total variance. Finally, for DCP, and apart from the 
others three EOCs, the (PEI/PSS) 5 sensor with $10 \mu \mathrm{m}$ interdigitated gold electrode had the highest semi-qualitative response with the first two components of the PCA, explaining $98.68 \%$ (see PCA data on Supplementary Materials, Figure S6d) of the total variance.
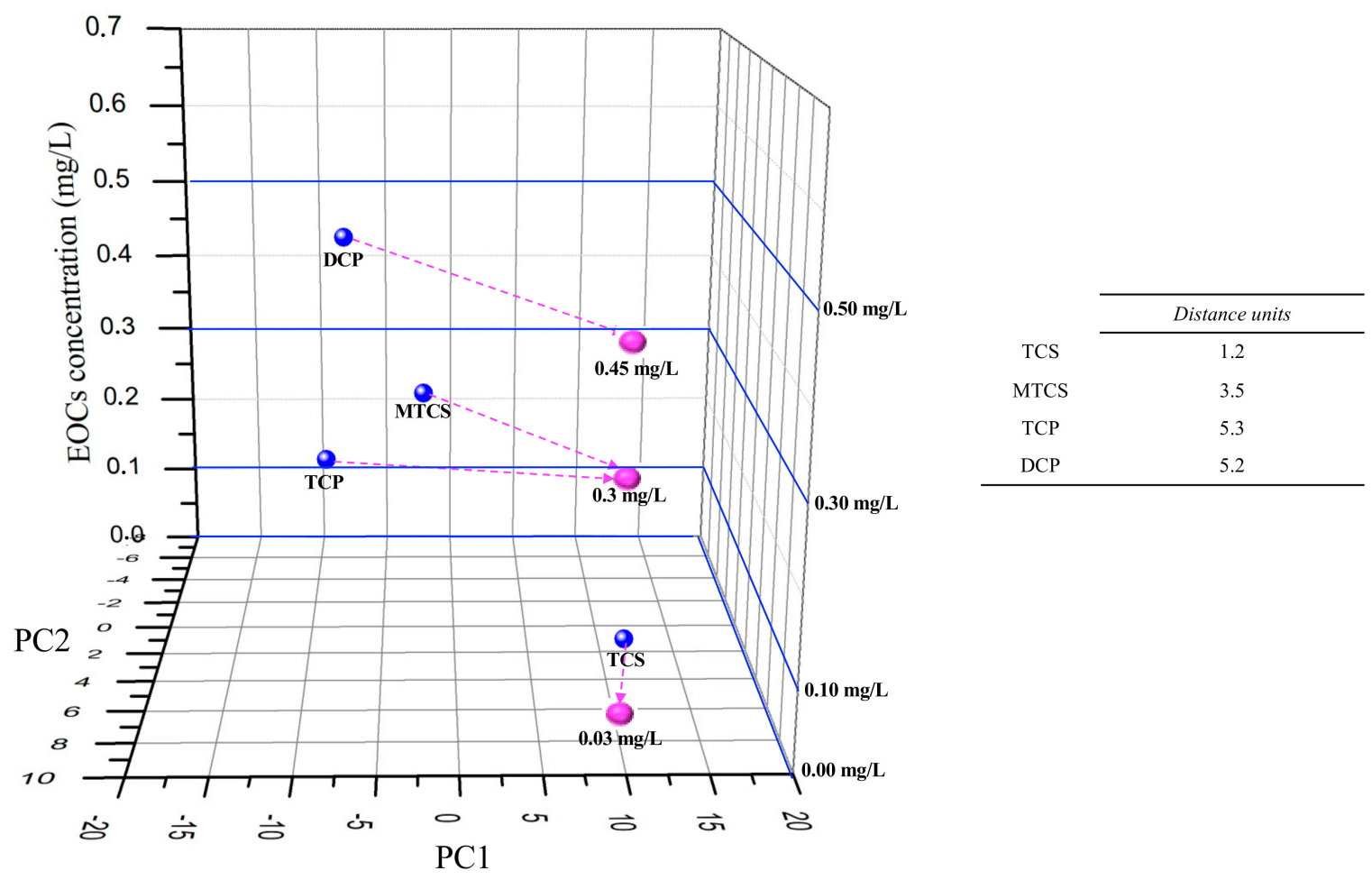

Figure 5. Visual evaluation of individual EOCs e-tongue semi-quantitative "sensorial signal" (individual vs mix measurements). Blue dots: EOCs Individual PC1 and PC2 data from Figure 3; Pink dots: high-performance liquid chromatography (HPLC) EOCs estimated concentrations for PC1 and PC2 data attained from Figure 4 at $\mathrm{t}_{120}$.

Figure 6 presents the same methodology for TCP and DCP, but only with $\mathrm{TiO}_{2}$ or $(\mathrm{PEI} / \mathrm{PSS})_{5}$ sensor impedance data for the semi-quantitative analyse of TCP and DCP.

Hence, analysing Figure 6, the distance between the interpolation points and the calibration points was lower (distance units decreased 3.2 to DCP and 1.8 to TCP), while comparing to Figure 5 e-tongue multisensory analyses for DCP and TCP.

The experimental data points to the importance of the nanomaterial used to build the e-tongue that will influence the impedance response as the thin film final morphology, structure, and properties of the thin films, and their consequent interactions with the different EOCs' physical-chemical behaviour on the effluent matrix [29].

According to [30] reported data, the thickness of the film is related to the hydrophobic or hydrophilic final character. Thus, the film presents a more hydrophobic character when the thickness is higher. The thin film morphology of the tested sensors, as presented at Figure 2a, suggests a hydrophilic character for all the films tested, although, as the thickness increases, the hydrophobic characters also increase (Figure $2 \mathrm{a}$, (PEI/PSS) $)_{5}<$ rough surface $<\mathrm{TiO}_{2} / \mathrm{ZnO}$ ). According to the experimental data, the thin films with more "hydrophobic character", due to film thickness, such as the $\mathrm{TiO}_{2} / \mathrm{ZnO}$ and $\mathrm{ZnO}$ thin films presented better impedance responses in the semi-quantitative analysis of TCS and M-TCS, the analytes with higher $\log \mathrm{k}_{\mathrm{ow}}$ (Table $\mathrm{S} 1$ in Supplementary Materials).

For the sensors that were considered to be "more hydrophilic", the $\mathrm{TiO}_{2}$ and (PEI/PSS) films presented the best responses for DCP and TCP, the less lipophilic analytes. To DCP, for instance, the higher porous size in the films with higher thickness, endorsed the molecule "semi-permeability" through the thin film net, "giving" to the molecules a fluid character, which may be masking their 
detection. Thus, in the $\mathrm{TiO}_{2} / \mathrm{ZnO}$ and $\mathrm{ZnO}$ thin films ("hydrophobic character"), the phenolic molecules movement will be faster than the detection, not allowing for the complete analysis understanding. In the polyelectrolytes thin film, (PEI/PSS) $)_{5}$, this behaviour does not occur, since the film layers are organic and without hole structures, only providing an impedance response to the electronegativity of the DCP and TCP, as the film combination is itself negatively charged.
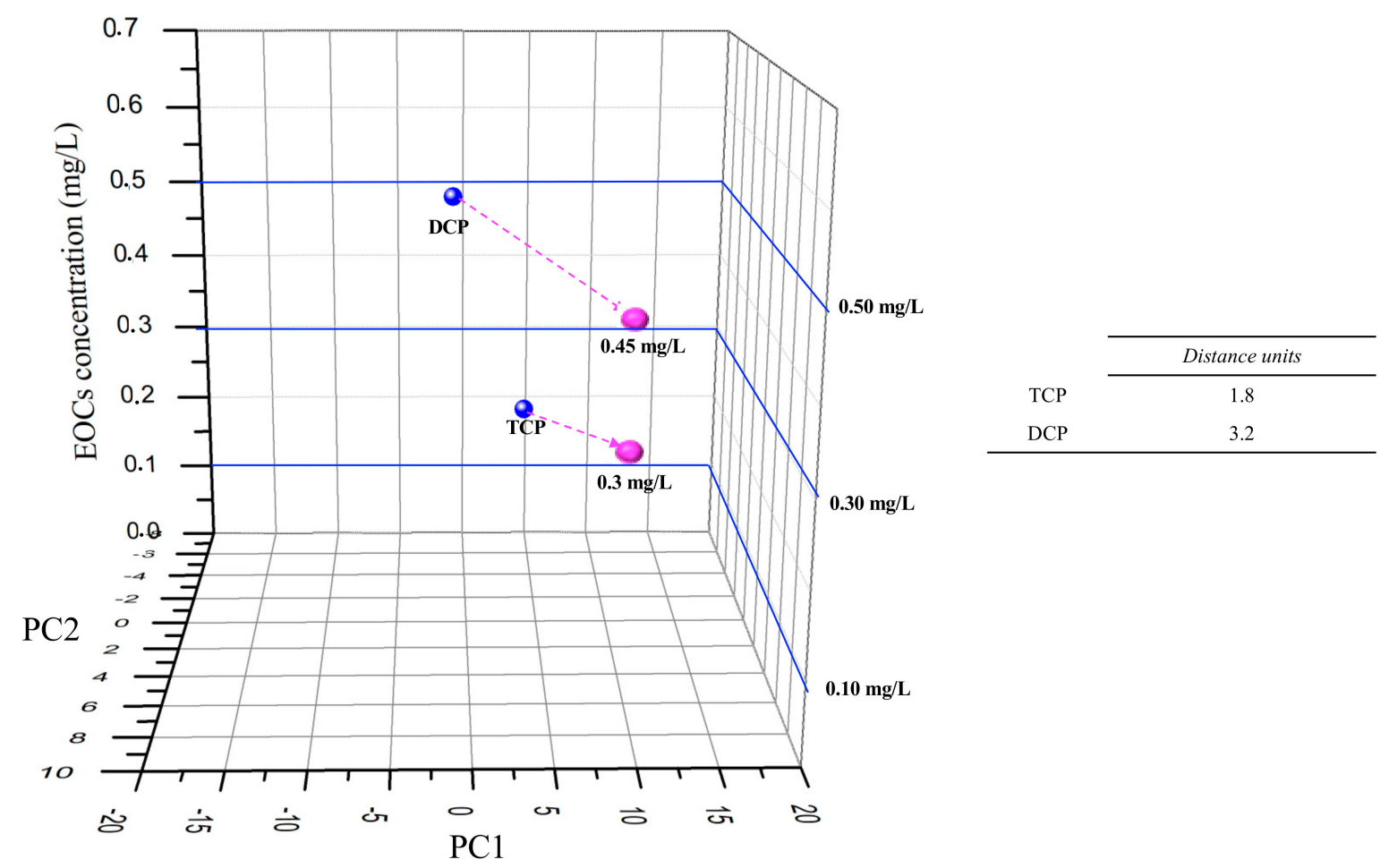

Figure 6. Visual evaluation of individual semi-quantitative "sensorial signal" (individual vs mix measurements) for TCP with $\mathrm{TiO}_{2}$ sensor and for DCP with (PEI/PSS) $)_{5}$ sensor. Blue dots: EOCs individual PC1 and PC2 data for TCP with $\mathrm{TiO}_{2}$ sensor and for DCP with (PEI/PSS) ${ }_{5}$ sensor; Pink dots: HPLC EOCs estimated concentrations for PC1 and PC2 data attained from Figure 4 at $\mathrm{t}_{120}$.

\section{Conclusions}

At an electrochemical reactor's outlet a customized e-tongue was attached, which was composed of five sensors, built up with layer-by-layer and sputtering thin-films, to access the degradation monitoring of TCS, M-TCS, DCP, and TCP. Three main issues were evaluated to analyse this hypothesis: (1) characterization of the thin-films; (2) e-tongue training for the recognition of the different EOCs; and, (3) e-tongue array performance in the detection and semi-quantification of the EOCs in a mix contaminated effluent. Therefore, performing impedance measurements into the e-tongue array, was observed analytes clustering by concentration in the calibration curves, where the first two components of the PCA explained $65.80 \%$ of the total variance. The e-tongue array showed responsiveness towards the EOCs decreasing concentrations during the electrochemical treatment, showing a pattern trend through the first two principal components, being explained by $77.27 \%$ of the total variance. The e-tongue recognized between individual EOCs-spiked effluents and raw effluent (non-spiked) matrices. At the end of the treatment, $\mathrm{t}_{120}$, the cross-check of the analytes individual semi-quantification was achieved for TCS and M-TCS with the e-tongue array. For DCP and TCP, better results were accomplished with a single sensor, (PEI/PSS) $)_{5}$ with $10 \mu \mathrm{m}$ interdigitated gold electrode and $\mathrm{TIO}_{2}$, respectively. The characterization of thin films, while using field emission scanning electron microscope, allowed for a total understanding of the "sensorial" impedance response. The present study suggests innovative alternatives for complementing the traditional analysis with sensors devices, 
since the customized e-tongue was capable of semi-qualitative analyses thought electro-dynamic degradation's kinetics.

Supplementary Materials: The following are available online at http://www.mdpi.com/1424-8220/19/24/5349/s1, Figure S1. Scheme of the thin films used in the electronic tongue array; Figure S2. Resistance impedance spectra of each sensor device under study to TCP; DCP, TCS and M-TCS; Figure S3. Resistance impedance spectra of each sensor device under study to the effluent spiked with $0.1 \mathrm{mg} / \mathrm{L}$ of TCP; DCP, TCS and M-TCS (Reproducibility of $\mathrm{n}=3$ impedance measurements); Figure S4. Electronic tongue calibration curves for each EOCs under study: TCP, DCP, TCS and M-TCS, in the range of concentration: 0-0.8 ppm (x axis): data from Figure 3, first component PC1 (y axis); Figure S5. EFR degradation path measured by an electronic tongue in the effluent with the 4 EOCs: 0 $\mathrm{mg} / \mathrm{L}$ (non-spiked; $\mathrm{t}_{0}$ to $\mathrm{t}_{120}$ (spiked with the $4 \mathrm{EOCs}$ ) sampled every $15 \mathrm{~min}$; Figure S6. PCA Score plot for the best sensors, concerning effluent spiked $(0-0.7 \mathrm{mg} / \mathrm{L})$ with the 4 EOCs. Table S1. Chemical properties of the EOCs under study; Table S2. Average and standard deviation error to the electronic tongue presented at Figure 4.

Author Contributions: Conceptualization, C.M. and S.S.; Data curation, C.M.; Formal analysis, E.P.M., J.M.P.-G., S.S., M.R. and A.B.R.; Funding acquisition, M.R. and A.B.R.; Methodology, C.M.; Project administration, M.R. and A.B.R.; Resources, E.P.M., M.R. and A.B.R.; Supervision, E.P.M., J.M.P.-G. and A.B.R.; Validation, E.P.M., J.M.P.-G., M.R. and A.B.R.; Writing-original draft, C.M.; Writing-review \& editing, C.M., E.P.M., J.M.P.-G., S.S and A.B.R.

Funding: This study was partially funded by Fundação para a Ciência e a Tecnologia through projects UID/AMB/04085/2019, UID/FIS/00068/2019 and PTDC/FIS-NAN/0909/2014. This work has received funding from the European Union's Horizon 2020 research and innovation programme under the Marie Skłodowska-Curie grant agreement No. 778045. C. Magro acknowledges Fundação para a Ciência e a Tecnologia for her PhD fellowship SFRH/BD/114674/2016.

Acknowledgments: This research was anchored by the RESOLUTION LAB, an infrastructure at NOVA School of Science and Technology. C. Magro acknowledges Fundação para a Ciência e a Tecnologia for her PhD fellowship SFRH/BD/114674/2016. The authors thank Ricardo Faria for his help with the reactors drawing.

Conflicts of Interest: The authors declare no conflict of interest.

\section{References}

1. United Nations. World Population Prospects 2019 (ST/ESA/SER.A/423); United Nations Department of Economic and Social Affairs: New York, NY, USA, 2019.

2. Corcoran, E.; Nellemann, C.; Baker, E.; Bos, R.; Osborn, D.; Savelli, H. Sick Water ? The Central Role of Wastewater Management in Sustainable Development; UNEP/Earthprint: Nairobi, Kenya, 2010; ISBN 9788277010755.

3. Daughton, C.G. Non-regulated water contaminants: Emerging research. Environ. Impact Assess. Rev. 2004, 24, 711-732. [CrossRef]

4. Geissen, V.; Mol, H.; Klumpp, E.; Umlauf, G.; Nadal, M.; Van Der Ploeg, M.; Van De Zee, S.E.A.T.M.; Ritsema, C.J. Emerging pollutants in the environment: A challenge for water resource management. Int. Soil Water Conserv. Res. 2015, 3, 57-65. [CrossRef]

5. Sirés, I.; Oturan, N.; Oturan, M.A.; Rodríguez, R.M.; Garrido, J.A.; Brillas, E. Electro-Fenton degradation of antimicrobials triclosan and triclocarban. Electrochim. Acta 2007, 52, 5493-5503. [CrossRef]

6. Daughton, C.G.; Ternes, T.A. Pharmaceuticals and personal care products in the environment: Agents of subtle change? Environ. Health Perspect. 1999, 107, 907-938. [CrossRef]

7. Rivera-Utrilla, J.; Sánchez-Polo, M.; Ferro-García, M.Á.; Prados-Joya, G.; Ocampo-Pérez, R. Pharmaceuticals as emerging contaminants and their removal from water. A review. Chemosphere 2013, 93, 1268-1287. [CrossRef]

8. López-Serna, R.; Petrović, M.; Barceló, D. Occurrence and distribution of multi-class pharmaceuticals and their active metabolites and transformation products in the Ebro River basin (NE Spain). Sci. Total Environ. 2012, 440, 280-289. [CrossRef]

9. Jurado, A.; López-Serna, R.; Vázquez-Suné, E.; Carrera, J.; Pujades, E.; Petrovic, M.; Barceló, D. Occurrence of carbamazepine and five metabolites in an urban aquifer. Chemosphere 2014, 115, 47-53. [CrossRef]

10. Paíga, P.; Santos, L.H.M.L.M.; Ramos, S.; Jorge, S.; Silva, J.G.; Delerue-Matos, C. Presence of pharmaceuticals in the Lis river (Portugal): Sources, fate and seasonal variation. Sci. Total Environ. 2016, 573, 164-177. [CrossRef]

11. Roberts, J.; Kumar, A.; Du, J.; Hepplewhite, C.; Ellis, D.J.; Christy, A.G.; Beavis, S.G. Pharmaceuticals and personal care products (PPCPs) in Australia's largest inland sewage treatment plant, and its contribution to a major Australian river during high and low flow. Sci. Total Environ. 2016, 541, 1625-1637. [CrossRef] 
12. Wu, Y.; Yu, C.P.; Yue, M.; Liu, S.P.; Yang, X.Y. Occurrence of selected PPCPs and sulfonamide resistance genes associated with heavy metals pollution in surface sediments from Chao Lake, China. Environ. Earth Sci. 2016, 75, 1-8. [CrossRef]

13. Aranami, K.; Readman, J.W. Photolytic degradation of triclosan in freshwater and seawater. Chemosphere 2007, 66, 1052-1056. [CrossRef] [PubMed]

14. Constantin, L.A.; Nitoi, I.; Cristea, N.I.; Constantin, M.A. Possible degradation pathways of triclosan from aqueous systems via TiO2 assisted photocatalyis. J. Ind. Eng. Chem. 2018, 58, 155-162. [CrossRef]

15. Hua, W.; Bennett, E.; Letcher, R. Triclosan in waste and surface waters from the upper Detroit River by liquid chromatography-electrospray-tandem quadrupole mass spectrometry. Environ. Int. 2005, 31, 621-630. [CrossRef] [PubMed]

16. McAvoy, D.C.; Schatowitz, B.; Jacob, M.; Hauk, A.; Eckhoff, W.S. Measurement of triclosan in wastewater treatment systems. Environ. Toxicol. Chem. 2002, 21, 1323-1329. [CrossRef]

17. Guo, J.-H.; Li, X.-H.; Cao, X.-L.; Li, Y.; Wang, X.-Z.; Xu, X.-B. Determination of triclosan, triclocarban and methyl-triclosan in aqueous samples by dispersive liquid-liquid microextraction combined with rapid liquid chromatography. J. Chromatogr. A 2009, 1216, 3038-3043. [CrossRef]

18. Balmer, M.E.; Poiger, T.; Droz, C.; Romanin, K.; Bergqvist, P.A.; Müller, M.D.; Buser, H.R. Occurrence of methyl triclosan, a transformation product of the bactericide triclosan, in fish from various lakes in Switzerland. Environ. Sci. Technol. 2004, 38, 390-395. [CrossRef]

19. Xing, L.; Sun, J.; Liu, H.; Yu, H. Combined toxicity of three chlorophenols 2,4-dichlorophenol, 2,4,6-trichlorophenol and pentachlorophenol to Daphnia magna. J. Environ. Monit. 2012, 14, 1677-1683. [CrossRef]

20. Zhao, N.; Li, X.; Jin, X.; Angelidaki, I.; Zhang, Y. Integrated electrochemical-biological process as an alternative mean for ammonia monitoring during anaerobic digestion of organic wastes. Chemosphere 2018, 195, 735-741. [CrossRef]

21. Vlasov, Y.; Legin, A.; Rudnitskaya, A.; Di Natale, C.; D'Amico, A. Nonspecific sensor arrays ("electronic tongue") for chemical analysis of liquids ( IUPAC Technical Report ). Pure Appl. Chem. 2005, 77, 1965-1983. [CrossRef]

22. Magro, C.; Mateus, E.P.; Raposo, M.; Ribeiro, A.B. Overview of electronic tongue sensing in environmental aqueous matrices: Potential for monitoring emerging organic contaminants. Environ. Rev. 2019, 27, 202-214. [CrossRef]

23. Mimendia, A.; Gutiérrez, J.M.; Leija, L.; Hernández, P.R.; Favari, L.; Muñoz, R.; del Valle, M. A review of the use of the potentiometric electronic tongue in the monitoring of environmental systems. Environ. Model. Softw. 2010, 25, 1023-1030. [CrossRef]

24. Campos, I.; Alcañiz, M.; Aguado, D.; Barat, R.; Ferrer, J.; Gil, L.; Marrakchi, M.; Martínez-Mañez, R.; Soto, J.; Vivancos, J.-L. A voltammetric electronic tongue as tool for water quality monitoring in wastewater treatment plants. Water Res. 2012, 46, 2605-2614. [CrossRef] [PubMed]

25. Cetó, X.; González-Calabuig, A.; del Valle, M. Use of a bioelectronic tongue for the monitoring of the photodegradation of phenolic compounds. Electroanalysis 2015, 27, 225-233. [CrossRef]

26. Facure, M.H.M.; Mercante, L.A.; Mattoso, L.H.C.; Correa, D.S. Detection of trace levels of organophosphate pesticides using an electronic tongue based on graphene hybrid nanocomposites. Talanta 2017, 167, 59-66. [CrossRef]

27. Liu, X.; Feng, H.; Liu, X.; Wong, D.K.Y. Electrocatalytic detection of phenolic estrogenic compounds at NiTPPS|carbon nanotube composite electrodes. Anal. Chim. Acta 2011, 689, 212-218. [CrossRef]

28. Oliveira, O.N.; Raposo, M.; Dhanabalan, A. Langmuir-blodgett and self-assembled polymeric films. In Handbook of Surfaces and Interfaces of Materials; Nalwa, H.S., Ed.; Elsevier: Burlington, NJ, USA, 2001; pp. 1-63. ISBN 978-0-12-513910-6.

29. Riul, A.; Dos Santos, D.S.; Wohnrath, K.; Di Tommazo, R.; Carvalho, A.C.P.L.F.; Fonseca, F.J.; Oliveira, O.N.; Taylor, D.M.; Mattoso, L.H.C. Artificial taste sensor: Efficient combination of sensors made from Langmuir-Blodgett films of conducting polymers and a ruthenium complex and self-assembled films of an azobenzene-containing polymer. Langmuir 2002, 18, 239-245. [CrossRef]

30. Paulovich, F.V.; De Oliveira, M.C.F.; Oliveira, O.N. A future with ubiquitous sensing and intelligent systems. ACS Sens. 2018, 3, 1433-1438. [CrossRef] 
31. Riul, A.; Dantas, C.A.R.; Miyazaki, C.M.; Oliveira, O.N. Recent advances in electronic tongues. Analyst 2010, 135, 2481-2495. [CrossRef]

32. Magro, C.; Zagalo, P.M.; Mateus, E.P.; Ribeiro, A.B.; Ribeiro, P.A.; Raposo, M. Triclosan Detection in Aqueous Environmental Matrices by Thin-films Sensors: Impedantiometric Electronic Tongue. In Proceedings of the 7th International Symposium on Sensor Science, Napoli, Italy, 9-11 May 2019; MDPI: Basel, Switzerland, 2019; pp. 1-4.

33. Zhu, X.; Tang, F.; Suzuki, T.S.; Sakka, Y. Role of the initial degree of ionization of polyethylenimine in the dispersion of silicon carbide nanoparticles. J. Am. Ceram. Soc. 2003, 86, 189-191. [CrossRef]

34. Raposo, M.; Lourenço, J.M.C.; Botelho do Rego, A.M.; Ferraria, A.M.; Ribeiro, P.A. Counterions - A new approach to control the degree of ionization of polyelectrolytes in layer-by-layer films. Colloids Surf. A Physicochem. Eng. Asp. 2012, 412, 1-10. [CrossRef]

35. Lourenço, J.M.C.; Ribeiro, P.A.; Do Rego, A.M.B.; Fernandes, F.M.B.; Moutinho, A.M.C.; Raposo, M. Counterions in poly(allylamine hydrochloride) and poly(styrene sulfonate) layer-by-layer films. Langmuir 2004, 20, 8103-8109. [CrossRef] [PubMed]

36. Zhu, B.L.; Xie, C.S.; Wang, W.Y.; Huang, K.J.; Hu, J.H. Improvement in gas sensitivity of ZnO thick film to volatile organic compounds (VOCs) by adding $\mathrm{TiO}_{2}$. Mater. Lett. 2004, 58, 624-629. [CrossRef]

37. Chaudhary, S.; Umar, A.; Bhasin, K.K.; Baskoutas, S. Chemical sensing applications of ZnO nanomaterials. Materials 2018, 11, 1-38. [CrossRef] [PubMed]

38. Siopa, D.; Sério, S.; Jorge, M.E.M.; Viana, A.S.; Gomes, A. ZnO seed layers prepared by DC reactive magnetron sputtering to be applied as electrodeposition substrates. J. Electrochem. Soc. 2016, 163, H697-H704. [CrossRef]

39. De Souza, N.C.; Silva, J.R.; Pereira-da-Silva, M.A.; Raposo, M.; Faria, R.M.; Giacometti, J.A.; Oliveira, O.N. Dynamic scale theory for characterizing surface morphology of layer-by-layer films of poly(o-methoxyaniline). J. Nanosci. Nanotechnol. 2004, 4, 548-552. [CrossRef]

(C) 2019 by the authors. Licensee MDPI, Basel, Switzerland. This article is an open access article distributed under the terms and conditions of the Creative Commons Attribution (CC BY) license (http://creativecommons.org/licenses/by/4.0/). 